\title{
Lipid composition of the brains of she-goat and castrated goat consumed in Ekiti State, Nigeria
}

\author{
E. I. Adeyeye* and A. J. Adesina
}

Department of Chemistry (Analytical Unit), Ekiti State University, PMB 5363, Ado-Ekiti, Nigeria.

\begin{abstract}
The levels of fatty acids, phospholipids and sterols were determined in the brains of she-goat and castrated goat found in Ekiti State, Nigeria by gas chromatography. Results showed that the crude fat levels were 9.98 and $10.2 \%$ in the brains of she-goat and castrated goat respectively. The fatty acid composition of she-goat and castrated goat brain shows that the SFA was 40.6 and $42.7 \%$, MUFA was 37.1 and $38.7 \%$ and PUFA was 20.9 and $22.3 \%$ respectively. The other parameters of she-goat and castrated goat brain were found: PUFA/SFA, 0.490 and 0.548; MUFA/SFA, 0.869 and $0.953 ; n-6 / n-3,0.775$ and 11.7 ; LA/ALA, 0.876 and 28.0; AA/DGLA, 6.05 and 17.4; EPA/DHA, 1.00 and 5.89 and EPSI (PUFA/MUFA), 0.564 and 0.575 respectively. Phospholipids were present in she-goat and castrated goat with a value range of 2365 and $3047 \mathrm{mg} / 100 \mathrm{~g}$ respectively. Among the sterols, only cholesterol was of any significant level with values of $1353 \mathrm{mg} / 100 \mathrm{~g}$ (she-goat brain) and $1355 \mathrm{mg} / 100 \mathrm{~g}$ (castrated goat brain). Linear correlation at $\alpha=0.05$, df: $\mathrm{n}-1$ showed that no significant difference exists between the crude fats, phospholipids and sterols except in the fatty acids parameters.
\end{abstract}

Keywords: Goat brain; Lipid composition; Fatty acid; Phospholipid; Sterol; Gas chromatograph

\section{Introduction}

The domestic goat (Capra aegagrus hircus) is a subspecies of goat domesticated from wild goat of Southwest Asia and Eastern Europe. The goat is a member of the family Bovidae and is closely related to the sheep as both are in the goatantelope subfamily Caprinae. There are over 300 distinct breeds of goat (Hirst, 2008). Goats are one of the oldest domesticated species, and have been used for their milk, meat, hair, and skin in most parts of the world. In 2011, there were more than 924 million live goats around the globe, according to the UN Food and Agriculture Organization (Anonymous, 1988). Norman (Norman, 1991) noted from several references that goats are concentrated in the drier regions of Brazil and Nigeria as well as in southern Africa. There are virtually no religious or culture taboos on the eating of goat meat; with the result that goat are readily available to societies in which eating beef, pork, or other meat types are prohibited. In many parts of the world goat is preferred to mutton and commands a better price (Casey, 1992).

Meat protein has a digestibility coefficient of $97 \%$ giving ingested meat heat combustion of $17.8 \mathrm{~kJ}$ (Gopalan et al., 1971). The average biological value of goat meat reported by Mitra and Mitra (1945), based on feeding trials with rats fed at $10 \%$ level of protein was $60.4 \%$ which was slightly lower than the $68.6 \%$ of beef. The nutrient value of muscle lies in the extent to which the protein and specifically the indispensable amino acid requirements of humans are satisfied. Pellet and Young (Pellet and Young, 1990) proposed that dietary protein quality should be determined in terms of two standards: that which is needed for infants, and for persons older than 2 years. The analyses of goat muscle are presented in terms of the later group. A greater intramuscular fat content which occurs at heavier masses and in older animals would decrease the relative content of other nutrients (Casey and Naude, 1984).

In many developing countries, meat animals are frequently slaughtered only for the carcass, whereas a number of byproducts which can be obtained quite easily could help to improve the supply of low cost, high protein foods for people. As regards the utilization of edible slaughter byproducts, most studies have concentrated on protein extraction, involving costly processing techniques of little or no practical interest to developing countries. Good profits can be achieved, however by utilizing byproducts as ingredients in meat production (Fornias, 1996). Meat animals yield, besides their carcass, a considerable amount of parts which are biologically and hygienically fit for human consumption. These byproducts are very different from the view of structure, proximate composition, functional or sensory properties, but they can all be used as food. They are generally consumed either as main ingredients in meat products (Adeyeye, 2013). Among byproducts which are edible is the brain which is consumed as direct meat products. A considerable literature has been published on the health benefits of fish, oil rich fish and fish oils and their constituent

\footnotetext{
*Corresponding author: E-mail: eiadeyeye@yahoo.com, adeyeyeilesanmi2012@gmail.com
} 
long chain $n$-3 PUFA. Adeyeye (Adeyeye, 2012) reported on the long- chain (n-6) and $n-3$ polyunsaturated fatty acids and other lipids in the brains of bull and hen. There is hardly any information on the lipid composition of brains of goat. The purpose of this paper therefore is to explore evidence relating to the lipid composition of the brains of she-goat and castrated goat as contributors to the availability of nutritionally valuable fatty acids when used as food.

\section{Materials and methods}

\section{Sample collection and treatment}

The brains of goats (she and castrated) were collected from butchers who daily slaughter goats for the meat from the slaughter house based in Ado- Ekiti. The brains were collected into clean glass Petri- dishes, covered and dried in air oven at a temperature between $60^{\circ} \mathrm{C}$ and $80^{\circ} \mathrm{C}$ for about 5 hours. After drying, the brains were made into fine powder and packed in airtight plastic sample bottles and kept in freezer $\left(-4^{\circ} \mathrm{C}\right)$ for analysis.

\section{Determination of ether extract}

An aliquot $(0.25 \mathrm{~g})$ of each sample was weighed in an extraction thimble and $200 \mathrm{ml}$ of petroleum ether $\left(40-60^{\circ} \mathrm{C}\right.$ boiling range) was added. The covered porous thimble containing the sample was extracted for $5 \mathrm{~h}$ using a Soxhlet extractor. The extraction flask was removed from the heating mantle when it was almost free of petroleum ether, oven dried at $105^{\circ} \mathrm{C}$ for $1 \mathrm{~h}$, cooled in a desiccator and the weight of dried oil was determined.

\section{Preparation of fatty acid methyl esters and analysis}

A $50 \mathrm{mg}$ aliquot of the dried oil was saponified for $5 \mathrm{~min}$ at $95{ }^{\circ} \mathrm{C}$ with $3.4 \mathrm{ml}$ of $0.5 \mathrm{M} \mathrm{KOH}$ in dry methanol. The mixture was neutralized by $0.7 \mathrm{M} \mathrm{HCl}$ and $3 \mathrm{ml}$ of $14 \%$ boron trifluoride in methanol was added. The mixture was heated for $5 \mathrm{~min}$ at $90^{\circ} \mathrm{C}$ to achieve complete methylation. The fatty acid methyl esters were thrice extracted from the mixture with redistilled $\mathrm{n}$-hexane and concentrated to $1 \mathrm{ml}$ for analysis. The fatty acid methyl esters were analysed using an HP 5890 powered with HP gas chromatograph [HP 5890 powered with HP ChemStation rev A09.01 (1206) software (GMI, Inc., Minnesota, USA)] fitted with a flame ionization detector. Nitrogen was used as the carrier gas with a flow rate of 20-60 ml/min. The oven programme was: initial temperature at $60^{\circ} \mathrm{C}$, ramping at $10^{\circ} \mathrm{C} / \mathrm{min}$ for $20 \mathrm{~min}$, held for $4 \mathrm{~min}$, with a second ramping at $15^{\circ} \mathrm{C} / \mathrm{min}$ for $4 \mathrm{~min}$ and held for $10 \mathrm{~min}$. The injection temperature was $250^{\circ} \mathrm{C}$ and the detector was $320^{\circ} \mathrm{C}$. A polar (HPINNOWAX) capillary column ( $30 \mathrm{~m} \times 0.25 \mathrm{~mm} \times 0.25 \mu \mathrm{m}$ ) was used to separate the esters. A split injection was used with a split ratio of 20:1. The peaks were identified by their relative retention time compared with known standards.

\section{Sterol analysis}

Aliquots of the dried oil were added to screw-capped test tubes. The sample was saponified at $95^{\circ} \mathrm{C}$ for $30 \mathrm{~min}$, using 3 $\mathrm{ml}$ of $10 \% \mathrm{KOH}$ in ethanol, to which $0.20 \mathrm{ml}$ of benzene was added to ensure miscibility. Deionised water $(3 \mathrm{ml})$ was added and $2 \mathrm{ml}$ of hexane was used in extracting the nonsaponifiable materials. Three extractions, each with $2 \mathrm{ml}$ of hexane, were carried out for $1 \mathrm{~h}, 30 \mathrm{~min}$ and $30 \mathrm{~min}$ respectively, to achieve complete extraction of the sterols. Hexane was concentrated to $1 \mathrm{ml}$ for gas chromatographic analysis. Other procedures followed as in the analysis for fatty acid methyl esters.

\section{Phospholipid analysis}

By using a modified method of Raheja and Co-workers (Raheja et al., (1973) $0.01 \mathrm{~g}$ of the dried oil was added to test tubes. Any remaining solvent was removed by passing a stream of nitrogen gas over the oil. Then $0.40 \mathrm{ml}$ of chloroform was added, followed by addition of $0.10 \mathrm{ml}$ of the chromogenic solution. The tube was heated to $100^{\circ} \mathrm{C}$ in a water bath for $1 \mathrm{~min} 20 \mathrm{sec}$., cooled to room temperature, 5 $\mathrm{ml}$ of hexane was added and the tube was shaken gently several times. After separation of the solvent and aqueous layers, the hexane layer was recovered and concentrated to $1.0 \mathrm{ml}$ for analysis. Analysis was performed using the gas chromatograph with a polar (HP5) capillary column (30 m x $0.25 \mathrm{~mm} \times 0.25 \mu \mathrm{m})$. The oven programme was: initially at $50^{\circ} \mathrm{C}$ ramping at $10^{\circ} \mathrm{C} / \mathrm{min}$ for $20 \mathrm{~min}$, held for $4 \mathrm{~min}$, a second ramping at $15^{\circ} \mathrm{C} / \mathrm{min}$ for $4 \mathrm{~min}$ and held for $5 \mathrm{~min}$. The injection temperature was $250^{\circ} \mathrm{C}$, and the detector temperature was $320{ }^{\circ} \mathrm{C}$. As previously described, a split injection type was used having a split ratio of 20: 1. Peaks were identified by comparison with known standards.

\section{Results and discussion}

Table I depicts total lipid and calculated total fatty acid levels on dry weight basis of brains of she-goat (G1) and castrated goat (I3). The values of total lipids between the two samples were very close with the $\mathrm{CV} \%$ of 1.54 . The total fat of 9.98 and $10.2 \mathrm{~g}$ were comparably lower than the value in duck's meat and skin (43\%), chicken's meat and skin (18.0\%), beef fat (67\%), lamb fat (72\%) and pork fat (71\%) (Bender, 1992); brains of bull and hen (42.5\% and $45.2 \%$ ) (Adeyeye, 2012) but comparably close to the value reported for the fat of cattle brain $(10.6 \%)$ wet weight with $77.6 \%$ water content and also comparably lower than the level reported for sheep brain (38.1\%) and pig brain (42.6\%) (Fornias, 1996). Table II shows the level of saturated fatty acids (SFA), monounsaturated fatty acids (MUFA) and polyunsaturated fatty acids in the two brain samples. In both samples the brain SFAs C2:0, C3:0, C4:0, C5:0, C6:0, C8:0, C10:0 and C12:0 recorded were $0.00 \%$. Similar observations have also been made in respect of the brains of bull and hen except that C14.0, C16:0, C18:0 and C20:0 were not at $0.0 \%$ level 
Table I. Crude fat, total fatty acids (\%) and energy (kJ/100g) of she-goat (G1) and castrated goat (I3)

\begin{tabular}{lccccc}
\hline Samples & G1 & I3 & Mean & SD & CV \% \\
\hline Crude fat & 9.98 & 10.2 & 10.1 & 0.156 & 1.54 \\
$\begin{array}{l}\text { Total fatty } \\
\text { acid* }\end{array}$ & 7.98 & 8.16 & 8.07 & 0.124 & 1.54 \\
Energy kJ/100g & 295 & 302 & 299 & 4.60 & 1.54 \\
\hline
\end{tabular}

(Adeyeye, 2012). Among the MUFA, both samples had 0.0\% value for C18:1 (trans-11). The highest concentrated SFA in the two samples (brains of she-goat and castrated goat) was C16:0 with values of $23.0 \%$ and $23.3 \%$, followed by C18:0 with values of $14.5 \%$ and $14.4 \%$. The levels of these two SFAs were comparably close to the levels reported for the testes of bull, bucks and African giant pouch rats (Adeyeye, 2013). The levels of $C 22: 0$ (0.510 and 0.469 \%) and $C 24: 0$ $(0.063$ and $0.058 \%)$ obtained in the present work were comparably lower than the levels reported for the brains of bulls and hen (Adeyeye, 2012). C22:0 and C24:0 have not been implicated in enhancing the level of low density lipoprotein (LDL) cholesterol unlike myristic acid (C14:0) and palmitic (C16:0) acids (Grundy, 1994). The MUFA levels were contributed by C14:1(cis-9), C16:1 (cis-9), C18:1 (cis-6), C18:1 (cis-9); C20:1(cis-11), C22:1 (cis-13) and C24:1 (cis-15). Their total values were C14:1 (0.181 - 0.167 \%), C16:1 (4.57 - $4.99 \%)$, C18:1 (16.7 - $14.9 \%)$, C18:1 cis-9 (14.4 - 17.7), C20:1 (0.693 - 0.521 \%), C22:1 (0.175 $0.161 \%)$ and $\mathrm{C} 24: 1(0.063-0.058 \%)$. Although the CV \% values were low in both SFA and MUFA showing homogeneity of the results, a close observation would show that the values in the brains of she-goat were correspondingly higher than in the brain of castrated goat. Some literature SFA values were ( $\%$ total fat): 6.11 and $6.54 \%$ ( brains of bull and hen) (Adeyeye, 2012); beef fat (43\%), lamb fat (50\%), pork fat $(37 \%)$, chicken's meat and skin $(33 \%)$, duck meat and skin $(27 \%)$ calf liver $(30 \%)$, with corresponding MUFA values of $48 \%, 39 \% ; 41 \%, 42 \%, 54 \%$ and $54 \%$ ( Bender, 1992). SFA of testes of bull (48.0\%), buck (45.1\%) and pouch rat $(27.0 \%)$ with corresponding MUFA values of $38.6 \%, 39.9 \%$ and $55.6 \%$ respectively (Adeyeye, 2013); all these SFA and MUFA values were closely comparable to the present SFA and MUFA levels of the brains of she-goat and castrated goat (SFA: 42.7 and 40.6 \%; MUFA: 37.1 and 38.7 $\%)$. These values on the other hand were much higher than the levels reported for the brains of bull and hen (Adeyeye, 2012). Also in Table II, polyunsaturated fatty acids (PUFA) were depicted (consisting of $n-6$ and $n-3$ in the samples). Among the $n-6$ family, C20:4 n-6, (cis) (arachidonic acid AA) was the most concentrated in both samples with value range of 5.87- $1.88 \%$ with a $\mathrm{CV} \%$ of 72.8 . Whilst total PUFA $n-6$ was $9.14 \%$ in the she-goat brain, it was $20.5 \%$ in the brain of castrated goat with a CV\% of 54.1. These values were comparably lower than that reported for the brains of bull and hen (39.0 and $35.4 \%$ ) (Adeyeye, 2012) but comparably higher than the levels reported for the testes of bull, bucks and giant pouch rats (Adeyeye, 2013). C18:2 (n-6 cis, trans -linoleic acid, conjugated linoleic acid, CLA) has a value of $0.233 \%$ (she-goat brain) and $0.214 \%$ (castrated goat brain) with $\mathrm{CV} \%$ of 6.01 Table II. One of the factors that affect the total lipid found in serving of meat is highly dependent upon the feeding regiment (Daley et al., 2010). CLA is a constituent of ruminant animals and exists as a general mixture of conjugated isomers of linoleic acid (LA). The (cis-9, trans -11, CLA isomer (rumenic acid or RA) accounts for up to $80-90 \%$ of the total CLA in ruminant products (Daley et al., 2010). Naturally occurring CLAs originate from two sources: bacterial isomerization and /or biohydrogenation of PUFA in the rumen and desaturation of trans fatty acids in the adipose tissue and mammary gland (Grinary et al., 2000, Sebart et al., 1999). Microbial biohydrogenation of LA and $\alpha$-LA by anaerobic rumen bacterium Butyrivibrio fibrisolvens is highly dependent on rumen $\mathrm{pH}$. Grain consumption decreases rumen $\mathrm{pH}$ thereby reducing $B$. fibrisolvens activity, conversely grass based diets provide for a more favourable rumen environment for subsequent bacterial synthesis (Daley et al., 2010). Rumen pH might help explain apparent differences in CLA content between grain (mostly for the birds e.g hen), and grass (mostly for herd)-finished products. CLA has been shown in action to reduce carcinogenesis, atherosclerosis and onset of diabetes (Adeyeye, 2012). Considering the $n$-3 PUFA group, C22:6, (docosahexadienoic acid, DHA) has the higher levels in the brain of she-goat with a value of $10.7 \%$ whereas the value in castrated goat was $0.00 \%$. The total PUFA from literatures were: 85.0 (brain of hen) and $83.5 \%$ (brian of bull) (Adeyeye, 2012), beef fat (40\%), lamb fat (5\%), pork fat (15 $\%)$, chicken's meat and skin (19\%), duck meat and skin (12 $\%$ ) and calf liver (26\%) (Bender, 1992). Whilst the levels in the present results were comparably higher (total PUFA, 20.9 
Table II. Fatty acids composition (\%) of the brains of she-goat (G1) and castrated goat (I3) as well as their food and energy values

\begin{tabular}{|c|c|c|c|c|c|c|}
\hline \multirow[t]{2}{*}{ Fatty acids } & \multicolumn{2}{|c|}{$\%$ values } & \multicolumn{2}{|c|}{ As food values } & \multicolumn{2}{|c|}{ Energy in $\mathrm{kJ} / 100 \mathrm{~g}$} \\
\hline & $\mathrm{G} 1$ & 13 & G1 & 13 & G1 & 13 \\
\hline C14:0 & 4.09 & 1.83 & 0.33 & 0.15 & 12.1 & 5.54 \\
\hline C16:0 & 23.0 & 23.3 & 1.8 & 1.905 & 67.9 & 70.5 \\
\hline C18:0 & 14.5 & 14.4 & 1.2 & 1.177 & 42.8 & 43.6 \\
\hline C2O:O & 0.553 & 0.509 & 0.044 & 0.042 & 1.63 & 1.54 \\
\hline $\mathrm{C} 22: 0$ & 0.510 & 0.469 & 0.041 & 0.038 & 1.51 & 1.42 \\
\hline C24:0 & 0.063 & 0.058 & 0.005 & 0.005 & 0.19 & 0.175 \\
\hline TotalSFA & 42.7 & 40.6 & 3.4 & 3.32 & 126 & 123 \\
\hline C14:1(cis-9) & 0.181 & 0.167 & 0.014 & 0.014 & 0.53 & 0.505 \\
\hline C16:1(cis-9) & 4.67 & 4.99 & 0.37 & 0.408 & 13.8 & 15.1 \\
\hline C18:1(cis-6) & 16.7 & 14.9 & 1.3 & 1.22 & 49.3 & 45.1 \\
\hline C18:1(cis-9) & 14.2 & 17.7 & 1.1 & 1.45 & 41.9 & 53.5 \\
\hline C20:1 (cis-11) & 0.69 & 0.521 & 0.055 & 0.043 & 2.05 & 1.58 \\
\hline C22:1(cis-13) & 0.18 & 0.161 & 0.014 & 0.013 & 0.52 & 0.49 \\
\hline C24:1(cis-15) & 0.06 & 0.058 & 0.005 & 0.005 & 0.19 & 0.18 \\
\hline Total MUFAcis & 36.7 & 38.5 & 2.9 & 3.15 & 108 & 116 \\
\hline C18:1(trans6) & 0.199 & 0.183 & 0.016 & 0.015 & 0.59 & 0.554 \\
\hline C18:1(trans9) & 0.02 & 0.017 & 0.002 & 0.001 & 0.06 & 0.051 \\
\hline C18:1(trans 11$)$ & 0.00 & 0.00 & 0.00 & 0.00 & 0.00 & 0.00 \\
\hline Total MUFAtrans & 0.219 & 0.200 & 0.017 & 0.016 & 0.65 & 0.605 \\
\hline MUFA btal & 36.9 & 38.7 & 2.9 & 3.16 & 109 & 117 \\
\hline C20:2(cis-11,14) & 0.078 & 0.072 & 0.006 & 0.006 & 0.23 & 0.218 \\
\hline $\begin{array}{l}\text { C20:5(cis-5, } 8,11,14,17) \\
\text { C22:6(cis- }\end{array}$ & 0.37 & 0.058 & 0.030 & 0.005 & 1.10 & 0.175 \\
\hline $4,7,10,13,16,19)$ & 10.7 & 0.000 & 0.85 & 0.00 & 31.6 & 0 \\
\hline Total $(n-3)$ & 11.1 & 0.13 & 0.89 & 0.01 & 32.9 & 0.39 \\
\hline C18:2(cis-9,12) & 0.61 & 14.6 & 0.05 & 1.19 & 1.79 & 44.2 \\
\hline C18: 2(trans9,11) & 0.23 & 0.214 & 0.019 & 0.017 & 0.69 & 0.65 \\
\hline C18:3(cis-6,9,12) & 0.82 & 0.853 & 0.066 & 0.070 & 2.43 & 2.58 \\
\hline C18:3(cis-9,12, 15) & 0.56 & 0.921 & 0.045 & 0.075 & 1.65 & 2.79 \\
\hline C20:3(cis-8,11,14) & 0.65 & 1.620 & 0.05 & 0.132 & 1.91 & 4.90 \\
\hline C20:3(cis-11,14,17) & 0.338 & 0.311 & 0.027 & 0.025 & 1.00 & 0.94 \\
\hline C20:4(cis-5,8,11,14) & 5.87 & 1.88 & 0.47 & 0.15 & 17.3 & 5.69 \\
\hline C22:2(cis-13,16) & 0.06 & 0.058 & 0.005 & 0.005 & 0.19 & 0.18 \\
\hline Total $(n-6)$ & 9.14 & 20.5 & 0.7 & 1.67 & 27.0 & 61.9 \\
\hline PUFA btal & 20.2 & 22.3 & 1.6 & 1.823 & 59.7 & 67.5 \\
\hline Grand total & 99.80 & 99.9 & 8.0 & 8.168 & 295 & 302 \\
\hline
\end{tabular}

$\%$ and $22.3 \%$ respectively) than others, it was favourably comparable to chicken's meat and skin (19\%) and calf liver $(26 \%)$ (Bender, 1992). DHA is required in a large amount by the human brain, low DHA levels have been associated with low brain serotonin levels, which are connected to an increased tendency for depression and suicide. Several studies have established a correlation between low levels of $n$-3 fatly acids and depression. High consumption of $n-3$ FAs is typically associated with a lower incidence of depression, a decreased prevalence of age-related memory loss and a lower risk of developing Alzheimer disease (Laugharne, 1996). 
Casey and Co-workers (Casey and Van Niekerk, 1985) and Casey and Co-workers(Casey et al., 1988) have reported that the profile of the long chain fatty acids of goat meat showed oleic acid (C18:1) to be the most abundant with palmitic (C16:0) and stearic acid (C18:0) being relatively high. Nutritional influences on the fatty acid profile of ruminants are less than monogastric animals. It would appear however, that nutrition could cause subtle changes in ruminants including goats (Casey et al., 1985). PUFA ( $n-3$ and $n-6)$ are essential, that is human must consume them in the diet, the two groups compete for the same metabolic enzymes, thus the $n-6: n-3$ ratio will significantly influence the ratio of the ensuing eicosanoids (hormones) (like prostaglandins, leukotrienes, thromboxanes, e.t.c.) and will alter the body's metabolic function (Hooper et al., 2006). Generally, grass-fed animals accumulate more $n-3$ than do grain-fed animals which accumulate relatively more $n-6$. Metabolites of $n-6$ are significantly more inflammatory especially arachidonic acid (AA) than those of $n-3$. This requires that $n-3$ and $n-6$ are consumed in balanced proportion: healthy ratios of $n-6 / n-3$ range from $1: 1$ to $4: 1$. The samples under consideration have the $n-6 / n-3$ ratio of $0.775: 1$ (she-goat brain) and $11.7: 1$ (brain of castrated goat). Typical western diets provide ratios of between 10:1 and 20:1, that is dramatically skewed toward $n-6$ (Ruxton et al., 2005). The ratios of $n-6 / n-3$ in the present samples are fairly comparable to some ratios provided in the literatures. Here are some of the ratios provided for some common oils: canola $2: 1$, soybean 7:1, olive 3-13:1, sunflower (no $n-3$ ), flax 1:3, cotton seed (almost no $n-3$ ), peanut (no $n-3$ ), corn oil 46:1, brain of bull 0.2:1, brain of hen 0.125:1 (Adeyeye, 2012).

The relative amounts of PUFA and SFA in dietary fat/oil is important in nutrition and health. The ratio of PUFA/SFA ( $\mathrm{P} / \mathrm{S}$ ratio) is therefore important in determining the detrimental effects of dietary fats. The higher the $\mathrm{P} / \mathrm{S}$ ratio the more nutritionally useful is the dietary fat/oil. This is because the severity of atherosclerosis is closely associated with the proportion of the total energy supplied by SFAs and PUFAs (Honatra, 1974). The present PUFA/SFA levels were: 0.490 (she-goat brain) and 0.575 (castrated goat brain). These ratios were low but comparable to the values reported for the brains of bull (0.274) and buck (0.329) (Adeyeye, 2013). From several in-vivo and in-vitro studies with different animal species it is well known that ALA, LA and oleic acid (C18:1, $n$-9) compete for the same $\alpha$-desaturase in the metabolic cascade. Dietary studies on rats and other animals have shown that ALA is a strong suppressor of $n-6$ fatty acids metabolism, whereas 10 times as much LA is required to give an equal suppression of $n-3$ metabolism (Holman, 1998). The $n-6$ and $n-3$ FAs have critical roles in the membrane structure (Kinsella, 1990) and as precursors of eicosanoids, which are potent and highly reactive compounds. Since they compete for the same enzymes and have different biological roles, the balance between the $n-6$ and $n-3$ FAs in diet can be of considerable importance (Anonymous, 1994). The ratio of $n-6$ to $n-3$ or specifically LA to ALA in the diet should be $5: 1$ and 10:1 (WHO/FAO, 1994) or 4-10 g of $n-6$ FAs to $1.0 \mathrm{~g}$ of $n-3$ FAs. As LA is almost always present in food it tends to be relatively more abundant in animal tissues. This is supported in the present report as follows from LA/ALA ratios which were: $0.876: 1$ (she-goat brain) and 28:1 in castrated goat brain. The implication of this is that whilst it would be easy for the body to synthesis AA (C20:4 (n-6)) from $(\mathrm{C} 18: 2(n-6))$, it may be difficult to synthesize the $n-3$ PUFA series especially eicosapentaenoic acid (20:5 (n-3) or EPA) because of the low level of C18:3 (n-3) and so the diet must be enhanced in this PUFA. The relative proportion of MUFA/SFA is an important aspect of phospholipid composition and changes to this ratio have been claimed to have effects on such disease states as cardiovascular disease, obesity, diabetes, neuropathological conditions and cancer (Adeyeye, 2013). The MUFA/SFA levels in the samples were 0.869 (she-goat brain) and 0.953 (castrated goat brain) which were better than in PUFA/SFA levels $(0.490$ and 0.505 respectively). For example, MUFA/SFA has been shown to have cytoprotective actions in pancreatic $\beta$-cell. Cis-monoenoic acids have desirable physical properties for membrane lipids in that they are liquid at body temperature, yet are relatively resistant to oxidation. They are recognized by nutritionists as being beneficial in the human diet.

Several clinical studies show that insulin resistance is related to fatty acid composition (Borkman et al., 1993; Storen et al., 2007). Insulin resistance is characterized by specific changes of the composition of fatty acids in the serum lipids and in skeletal muscle membranes. Impaired insulin sensitivity is associated with high proportions of palmitic acid (16:0) and how levels of linoleic acid in serum. In addition, there are apparent changes of FA desaturase activities suggesting an increased activity of the $\Delta-9$ desaturase. Experimental studies have indicated that insulin activates the $\Delta-9$ and $\Delta-6$ desaturases. In experimental diabetes and in spontaneously diabetes rats, there are reduced activities of $\Delta-9, \Delta-6$, and $\Delta-5$ liver microtonal desaturases, which are restored after insulin treatment (Mimouni and Poisson, 1992). Moreover, in-vitro studies, evidenced that an increased unsaturation and a decreased ratio of $n-6 / n-3$ FAs in the muscle membrane are compatible with an increased membrane fluidity, findings that have been linked to the presence of an increased insulin receptors and an increased insulin binding (Ginsberg et al., 1982). The AA /DGLA values of 17.4 (she-goat brain) and 6.05 (castrated goat brain), which were all favourable to high AA/DGLA ratio leading to good insulin sensitivity. These FAs can be essential PUFA status makers: the best known maker is mead acid (C20:3, $n$-9). The synthesis of this FA is promoted if there are insufficient concentrations of LA and ALA to meet the need for the synthesis of long-chain PUFA. 
Table III. Phospholipids (mg/100g) contents of the brains of she-goat (G1) and castrated goat (I3)

\begin{tabular}{lccccc}
\hline Phospholipids & G1 & I3 & Mean & SD & CV \% \\
\hline $\begin{array}{l}\text { Phosphatidylethanolamine } \\
\text { (PE) }\end{array}$ & 521 & 357 & 439 & 116 & 26.4 \\
Phosphatidylcholine (PC) & 849 & 1320 & 1085 & 333 & 30.7 \\
Phosphatidylserine (PS) & 447 & 797 & 622 & 247 & 39.8 \\
Lysophosphatidylcholine & 6.84 & 9.49 & 8.17 & 1.87 & 22.9 \\
Phosphatidylinositol (PI) & 548 & 572 & 560 & 17.0 & 3.0 \\
Total & 2365 & 3047 & 2706 & 482 & 17.8 \\
\hline
\end{tabular}

EPA and DHA inhibit mead acid synthesis; the presence of mead acid indicates a general shortage of all essential PUFA. Another indicator of essential PUFA status is the essential PUFA status index (EPSI), which is the ratio between all essential PUFA (the sum of $n-3$ and $n-6$ fatty acids) and all non-essential unsaturated fatty acids (the sum of all $n-7$ and $n-9$ fatty acids). The higher the EPSI the better the essential PUFA status. The EPSI values in the brains of she-goat and castrated goat were 0.564 and 0.575 respectively. These values were higher compared with what was reported for testes of bull, bucks and giant pouch rats (Adeyeye, 2012). If there is a functional shortage of DHA, the body starts to synthesize the most comparable long-chain PUFA of the $n-6$ family, osbond acid (C22:5, n-6) therefore under steady state conditions, the ratio between DHA and osbond acid (all cis-4, $7,10,13,16)$ is a reliable indicator of the functional DHA status (Neuringer et al., 1986). In the present report interestingly, the ratios of EPA/DHA were: 5.89:1 (she-goat brain) and 1.00:1 (castrated goat brain).

Table II also shows the fatty acid distribution of she-goat and castrated goat brains as food. The values produced from SFA and MUFA were consistently higher than the levels produced by PUFAs in both the she-goat and castrated goat brains. The major contributions among the SFAs come from C16:0 and $\mathrm{C} 18: 0$ with values in $\mathrm{g} / 100 \mathrm{~g}$ ranging between $1.84-1.91$ (C16:0) and 1.16-1.18 (C18:0) for she-goat and castrated goats brains respectively whereas among the MUFAs, the major contributors were (18:1 (cis -6) and (18:1(cis-9). However, the total contributions from PUFA were 1.67 (she-goat brain) and 1.82 (castrated goat brain).
The energy contributions from fatty acids are shown in Table II where SFA was the major contributor with values of 126 $\mathrm{kJ} / 100 \mathrm{~g}$ (she-goat brain) and $123 \mathrm{~kJ} / 100 \mathrm{~g}$ (castrated goat brain) followed by MUFA which contributed $109 \mathrm{~kJ} / 100 \mathrm{~g}$ (she-goat brain) and $116 \mathrm{~kJ} / 100 \mathrm{~g}$ (castrated goat brain) and then PUFA group being the least contributors: $61.9 \mathrm{~kJ} / 100 \mathrm{~g}$ (she-goat brain) and $67.5 \mathrm{~kJ} / 100 \mathrm{~g}$ (castrated goat brain). The trend in energy contributions from these fatty acids group is SFA $>$ MUFA $>$ PUFA.

Table III shows the levels of various phospholipids in the sample. Phospholipids are not essential nutrients: they are just another lipid and as such, contribute $9 \mathrm{kcal} / \mathrm{g}$ of energy. Minor contributor to the phospholipids level was lysophosphatidylcholine that contribute less than $10 \mathrm{mg} / 100 \mathrm{~g}$ in each of the brain samples. The actual values being: 6.84 $\mathrm{mg} / 100 \mathrm{~g}$ (she-goat brain) and $9.49 \mathrm{mg} / 100 \mathrm{~g}$ (castrated goat brain). These values amount to 0.289 and $0.311 \%$ of the total phospholipid respectively. The total phospholipids level ranged between 2365 and $3047 \mathrm{mg} / 100 \mathrm{~g}$ for she-goat and castrated goat brains respectively showing the brains of these animals to be high in phospholipids content. The highest phospholipid was lecithin (phosphatidycholine) with values of $849 \mathrm{mg} / 100 \mathrm{~g}$ in she-goat brain and $1320 \mathrm{mg} / 100 \mathrm{~g}$ in castrated goat brain. This was followed by phosphatidylinositol in the she-goat brain [548 mg/l00g (23.2 $\%)$ ] and phosphasidylserine in the castrated goat brain (797 $\mathrm{mg} / \mathrm{l00 \textrm {g }}$ ) or $26.2 \%$. The levels of phospholipids in the present study was better than the levels reported for the brains of bull, buck and hen (Adeyeye, 2013). Phosphatidylcholine plays a role in membrane-mediated cell signaling and PCTP (Phosphatidylcholine Transfer Protein) activation of other enzymes (Kanno et al., 2007). At birth and throughout 
Table IV. Sterols (mg/100g) contents of the brains of she-goat (G1) and castrated goat (I3)

\begin{tabular}{|c|c|c|c|c|c|}
\hline Sterol & G3 & I3 & Mean & SD & $\mathrm{CV} \%$ \\
\hline Cholesterol & 1353 & 1355 & 1354 & 1.41 & 0.104 \\
\hline Cholestanol & $4.09 e-4$ & $2.66 \mathrm{e}-4$ & $3.38 \mathrm{e}-4$ & $1.01 \mathrm{e}-4$ & 30.0 \\
\hline Ergosterol & $2.90 \mathrm{e}-4$ & $1.71 \mathrm{e}-3$ & $1.00 \mathrm{e}-3$ & $1.00 \mathrm{e}-3$ & 100 \\
\hline Campesterol & $5.04 \mathrm{e}-3$ & $5.14 \mathrm{e}-4$ & 2.78 e -3 & $3.20 \mathrm{e}-3$ & 115 \\
\hline Stigmasterol & $1.66 \mathrm{e}-3$ & $1.64 \mathrm{e}-3$ & $1.65 \mathrm{e}-3$ & $1.41 \mathrm{e}-3$ & 0.857 \\
\hline 5- Avenasterol & 8.85 e -3 & 8.85 e -3 & 8.85 e -3 & 0.00 & 0.00 \\
\hline Sitosterol & $6.40 \mathrm{e}-3$ & $6.39 \mathrm{e}-3$ & $6.40 \mathrm{e}-3$ & $7.07 e-6$ & 0.111 \\
\hline Total & 1353 & 1355 & 1354 & 1.43 & 0.105 \\
\hline
\end{tabular}

Table V. Statistical analysis of the results

\begin{tabular}{lcccccccc}
\hline Group of parameters & $\mathrm{r}_{\mathrm{xy}}$ & $\mathrm{r}_{\mathrm{xy}}{ }^{2}$ & $\mathrm{CA}(\%)$ & $\mathrm{IFE}(\%)$ & $\mathrm{TV}$ & $\dot{\mathrm{X}}$ & $\overline{\mathrm{Y}}$ & $\mathrm{Remark}$ \\
\hline Crude fat, total fatty acids and energy (G3/I3) & 1.000 & 1.000 & 0.00 & 100 & - & 104 & 107 & $\mathrm{NS}$ \\
fatty acids parameters (G1/I3) & 0.7965 & 0.6344 & 60.5 & 39.5 & 0.48 & 3.84 & 6.98 & $\mathrm{~S}$ \\
Phospholipids (G1/I3) & 0.9816 & 0.9634 & 19.1 & 80.9 & 0.95 & 789 & 1017 & $\mathrm{NS}$ \\
Sterols (G1/I3) & 1.000 & 1.000 & 0.00 & 100 & 0.81 & 338 & 338 & $\mathrm{NS}$ \\
\hline
\end{tabular}

$\mathrm{TV}=$ table value at $\alpha=0.05, \mathrm{n}-1=2, \mathrm{CA}_{\mathrm{A}}=$ coefficient of alienation, $\mathrm{IFE}=\mathrm{index}$ of forecasting efficiency

infancy, phosphatidylcholine concentrations are high (as high as $90 \%$ of the cell membrane), but it is slowly depleted to as low as $10 \%$ of the cellular membrane in the elderly. As is such, some researchers in the fields of health and nutrition have begun to recommend daily supplementation of phosphatidylcholine as a way of slowing down senescence (Mci - Chu et al., 2001) and improving brain functioning and memory capacity (Chung et al., 1995). In addition to the increased caloric burden of a diet rich in fats like phosphatidylcholine, a recent report has linked the microbial catabolites of phosphatidylcholine with increased atherosclerosis through the production of choline, trimethylamine oxide and betaine (Wang et al., 2011). Phosphatidylethanolamine is found in all living cells, although in human physiology it is found particularly in nervous tissue such as the white matter of brain, nerves, neural tissue and in spinal cord. The US Food and Drug Administration (USFDA) have stated that consumption of phosphatidylserine (PS) may reduce the risk of cognitive dysfunction in the elderly (Adeyeye and Oyarekua, 2011). Phosphatidylserine (Ptd-L-Ser or PS) is a phospholipid component, usually kept on the inner leaflet, the cytosolic side, of cell membranes by an enzyme called flippase. Early studies of PS distilled the chemical from bovine brain. Because of concerns about Bovine Spongiform Encephalopathy, however, modern studies and commercially available products are made from soybeans. Preliminary studies indicate that the soyproduct is at least as effective as that of bovine origin (Blockland et al., 1999; Crook and Klatz, 1998). PS has been demonstrated to speed up recovery, prevent muscle soreness, improve well-being, and might possess ergogenic properties in athletes involved in cycling, weight training and endurance running. Soy-PS, in a dose dependent manner (400 mg), has been reported to be an effective supplement for combating exercise-induced stress by blunting the exercise induced increase in cortisol levels 
(Jäger et al.,2007). PS supplementation promotes a desirable hormonal balance for athletes and might attenuate the physiological deterioration that accompanies overtraining and/or overstretching (Starks et al., 2008). In recent studies, PS has been shown to enhance mood in a cohort of young people during mental stress and to improve accuracy during tee- off by increasing the stress resistance of golfers (Hirayama et al., 2006). First pilot studies indicate that PS supplementation might be beneficial for children with attention-deficit hyperactivity disorder (Vaisman et al ., 2008). Traditionally, PS supplements were derived from bovine cortex (BC-PS); however, due to the potential transfer of infectious diseases, soy-derived PS (S-PS) has been established as a save alternative. Soy-derived PS is generally recognized as safe (GRAS) and is a safer nutritional supplement for older persons if taken up to a dosage of 200 $\mathrm{mg}$ three times daily (Jorissen et al., 2002).

The sterol results in Table IV showed the values to be high for cholesterol in both of the samples with values 1353 and $1355 \mathrm{mg} / 100 \mathrm{~g}$ representing percentage levels of 99.99 $99.99 \%$ making other types of sterols very irrelevant. Along with SFA, cholesterol in the cell membrane gives our cells necessary stiffness and stability. This is why serum cholesterol levels may go down temporarily when we replace SFA with polyunsaturated oils in the diets (Jones, 1997). Cholesterol acts as precursor to vital corticosterols, hormones that help us deal with stress and protect the body against heart disease and cancer and to the sex hormones like androgen, testosterone, estrogen and progesterone. Cholesterol is a precursor to vitamin $\mathrm{D}$, a very important fat-soluble vitamin needed for healthy bones and nervous system, proper growth, mineral metabolism, muscle tone, insulin production, reproduction and immune system function. The bile salts are made from cholesterol. Bile is vital for digestion and assimilation of fats in the diet. Recent research shows that cholesterol also acts as an antioxidant (Cranton and Frackelton, 1984). This is the likely explanation for the fact that cholesterol levels go up with age. As an antioxidant, cholesterol protects us against free radical damage that leads to heart disease and cancer. Cholesterol is needed for proper function of serotonin receptors in the brain (Engelberg, 1992). Serotonin is in the body's natural "feel-good" chemical, low cholesterol levels have been linked to aggressive and violent behaviour, depression and suicidal tendencies. Mother's milk is especially rich in cholesterol and contains a special enzyme that helps the baby utilize the nutrient. Babies and children need cholesterol-rich foods throughout their growing years to ensure proper development of the brain and nervous system. Dietary cholesterol plays an important role in maintaining the health of the intestinal wall (Alfi-Slater and Aftergood, 1980). This is why low cholesterol vegetarian diets can lead to leaky gut syndrome and other intestinal disorders. Cholesterol levels in literature from many animal protein sources were either lower or higher than the she-goat and castrated goat cholesterol levels. Values in mg/100 g were: fish (50-60), egg yolk (1260), meat and poultry (60-120), brain (2000-3000), liver (300-350) (Bender, 1992). Others were lean rabbit, (71), sheep brain (2200), ox liver (270), sheep (430), pig (260) and calf (370) (Paul and Southgate, 1978). Most authorities, but not all, recommend a reduction in dietary cholesterol to around $300 \mathrm{mg}$ or less per day (Bender, 1992). The cholesterols levels in the two samples (1353 and $1355 \mathrm{mg} /$ $100 \mathrm{~g}$ ) fell far above this value.

\section{Statistical analysis}

Statistically, in Table VIII, the linear correlation at $\alpha=0.05$, df: $n-1$ showed that no significant difference existed between the crude fats, phospholipids and sterols except in the fatty acids parameters. The IFE (\%) was highest for crude fat and sterols at 100, 80.9 for phospholipids and least for fatty acids parameters at $39.5 \%$ making it to have the highest degree of coefficient of alienation $\left(\mathrm{C}_{\mathrm{A}}\right)$ at $60.5 \%$. The high values of IFE in crude fat, sterols and phospholipids make the comparison of the two brains easy unlike in the fatty acids because of the IFE values.

\section{Conclusion}

The findings of this study showed that the crude fat levels were of slight unequal distribution, but fairly low, 9.98 and $10.2 \%$. The SFA was lower $(42.7 \%$ and $40.6 \%)$ than the total unsaturated fatty acids in both of the two brain samples $(58.0 \%$ and $61.0 \%$ ); thereby making the fats good for human health. The proportion of cholesterol neutral stearic FA (C18:0) was about equal with $14.5 \%$ (she-goat) and $14.4 \%$ (castrated goat). The cholesterol-elevating SFAs such as myristic (C14:0) and palmitic (C16:0) were $4.09 \%$ and $23.0 \%$ (she-goat); and 1.83 $\%$ and $23.3 \%$ (castrated goat). The phospholipids were generally high $(2365 \mathrm{mg} / 100 \mathrm{~g}$ and $3047 \mathrm{mg} / 100 \mathrm{~g})$ and will promote the good health of its consumers. The cholesterol was the only sterol of significance and was generally higher (1353 $\mathrm{mg} / 100 \mathrm{~g}$ and $1355 \mathrm{mg} / 100 \mathrm{~g}$ ) than the recommended daily intake of $300 \mathrm{mg}$ per day. On the whole, the brains would serve as good animal by-products in dietary fat sources.

\section{References}

Adeyeye EI (2012), Study of long chain n-6 and n-3 polyunsaturated fatty acids and other lipids in brais of bull and hen. Elixir Food Science, 47: 8599-8606.

Adeyeye EI (2013), Health Implications of the consumption of the dietary lipids in the testes of bulls, bucks and African giant pouch rats. Elixir Food Science, 54: 12555-12568.

Adeyeye EI and Oyarekua MA (2011), Lipid profile of the 
skin anduscle of freshwater sardine (Pellenula afzeliusi) nutritional/dietary implications. Bangladesh J Sci Ind Res., 46(4): 523- 532.

Alfin-Slater RB and Aftergood L (1980). Lipids, modern nutrition in health and disease 16th ed. Lea and Febiger. American Oil Chemists' Society, pp. 177-182.

Anonymous, FAO, (1988). Food and Agricultural Organization: statistics division, basic data unit, Rome, Italy.

Anonymous, WHO/FAO (1994), Fats and oil in human nutrition. Report of a joint expert consultation. FAO Food and Nutrition Paper 57. Rome.

Bender A (1992), Meat and meat products in human nutrition in developing countries. FAO, Food and Nutrition Paper, 53, FAO, Rome, Italy, pp. 46-47.

Blockland A, Honig W, Brouns F and Jolles J (1999), Cognition enhancing properties of subchronic phosphatidylserine (PS)treatment in middle-aged rats: comparison of bovine cortex PS with egg PS and soybean PS. Nutrition, 15(10): 778-783.

Borkman M, Storlien LH, Pan DA, Jenkins AB, Chisholm DJ and Campbell LV (1993), The relation between insulin sensitivity andthe fatty-acid composition of skeletal-muscle phospholipids.

Casey NH and Van Nierkerk WA (1985), Fatty acids composition of subcutaneous and kidney fat depots of Boar goats and the response to varying levels of maize-meal. South African Journal of Animal Science, 15: 60-62.

Casey NH (1992), Goat Meat in Human Nutrition. In preconference proceedings of $5^{\text {th }}$ International conference on goats. Pre-conference Proceedings. Indian Council of Agricultural Research, NewDelhi, 2(2): 582-598.

Casey NH (1982), Carcass and growth characteristics of four South African sheep breeds and the boar goat, DSc. Thesis, Department of livestock Science, Faculty of Agriculture, University of Pretoria, Republic of South Africa.

Casey NH and Naude RT (1984), Differential growth profiles of muscle and fat depots. In Proceedings of the Second International Conference on cattle and sheep breeding, Pretoria, RSA, 2: 12 .

Casey NH, Van Nierkerk WA and Spreeth EB (1988), Fatty acids composition of subcutaneous fat of sheep grazed on eight different pastures, Meat Science, 23: 55-63.

Chung S, Tomoe M, Eiko U, Kayoko U, Rieko H, Noriko Y, Yasnunobu M, Toyohiko K, Shigeru Y (1995), Administration of phosphatidylcholine increases brain acetycholine concentration and improves memory in mice with dementia. The Journal of Nutrition, 125: 1484-1489.

Cranton EM and Frackelton JP (1984), Free radical pathology in ageassociated diseases: treatment with EDTA chelation, nutrition and antioxidants. Journal of Holistic Medicine, Spring/Summer 6(1): 6-37.

Crook TH and Klatz RM (eds) (1998). Treatment of age-related cognitive decline: effects of phosphatidylserine in anti-aging medical therapeutics. 2. Chicago: Health Quest Publications.

Daley CA, Abbort A, Doyle PS, Nader GA and Larson S (2010), Grass fed versus grain fed beef fatty acid profiles, antioxidant content and taste. Nutr. J., 9: 10-21.

Engelberg H (1992), Low serum Cholesterol and suicide. Lancet, 339: 727-728.

Fornias CV (1996), Edible by-products of slaughter animals. FAO Animal Production and Health. Paper 123, Rome, Italy.

Ginsberg BH, Jabour J and Spector AA (1982), Effects of alterations in membrane lipid unsaturation on the properties of the insulin receptor of Ehrlich as cites cells. Biochem Biophys Acta, 690: 157-164.

Gopalan C, RamaSastri BV and Balasubramaniam SC (1971), Nutritive value of Indian foods. National Institute of Nutrition, Hydrabad, India

Grinary JM, Corl BA, Lacy SH, Chouinard PY, Nurmela KV and Bauman DE (2000), Conjugated Linoleic acid is synthesized endogenously in the lactating dairy cows by $\Delta-9$ desaturase. Journal of Nutrition, 130: 2285-2291.

Grundy SM (1994), Influence of steric acid on cholesterol metabolism relative to other long-chain fatty acids, $\mathrm{Am}$ J Clin Nutr. 60(Supp): 986S - 990S.

Hirayama S, Masuda Y and Rabeler R (2006), Effect of phosphatidylserine administration on symptoms of attention deficit hyperactivity disorder in children. Agro Food, 17(5): 32-36.

Hirst KK (2008), The history of domestication of goats. http://www.About.com. Retrieved Jan., 2014.

Holman RT (1998), The slow discovery of the importance of omega-3 essential fatty acids in human health. Journal of Nutrition. 128: 427S-433S.

Honatra G (1974), Diatary fats and arterial thrombosis. Haemostrasis, 2: 21-52.

Honstra G (1992), Essential fatty acids, pregnancy and pregnancy complications: a roundtable discussion. In: 
Sinclair A, Gibson R eds. Essential fatty acids and eicosanoids Champaign, IL: American Oil Chemists' Society. pp. 177-182.

Hooper L, Thompson RL, Harrison RA, Summerbell CD, Ness AR, Moore HJ, Worthington HV, Domington PN, Higgins JPT, Capps NE, Riemersma RA, Ebrahim SBJ and Smith GD (2006), Risks and benefits of omega-3 fats for mortality, cardiovascular disease and cancer. Systematic review. British Medical Journal, 332: 752.

Jäger R, Purpura M, Geiss KR, Wei M, Baumeister J, Amatulli F, Schreder L and Herwegen H (2007), The effect of phosphatidylserine on golf performance. Journal of the International Society of Sports Nutrition, 4: 23.

Jones PJ (1997), Regulation of cholesterol biosynthesis by diet in humans. The Am J Clin Nutr.; 66(2): 438-446.

Jorissen BL, Brouns F, Van Boxtel MP and Riedel WJ (2002), Safety of soy-derived phosphatidylserine in elderly people. Nutr Neurosci., 5(5): 337-343.

Kanno K, Wu MK, Agate DA, Fanelli BK, Wagle N, Scapa EF, Ukomadu C and Cohen DE (2007), Interacting proteins dictate function of the minimal START domain phosphatidylcholine transfer protein/Star D2. $J$ Biol Chem, 282(42): 30728-30736.

Kinsella JE (1990), Possible mechanisms underlying the effects of n-3 polyunsaturated fatty acids. Omega-3 News. 5: 1-5.

Laugharne JDE (1996), Fatty acids and Schizophrenia. Lipids, 31: S163- S165.

Mei-Chu H, Koji S, Riki Y, Masao S and Katsumi I (2001), Learning behaviour and cerebral protein kinase C, antioxidant status, lipid composition in scene-accelarated mouse: influence of a phosphatidylcholine-vitamin B12 diet. British Journal of Nutrition, 86: 163-171.

Mimouni V and Poisson JP (1992), Altered desaturase activities andfatty acid composition in liver microsomes of spontaneously diabetic Wistar BB rat. Biochem Biophys Acta, 1123: 296-302.

Mitra K and Mitra HC (1945), Biological value of proteins from Muscle of cow, buffalo, and goat. Indian Journal of medical research, 33: 87-91.

Neuringer M, Connor WE, Lin DS, Barstad L and Luck S (1986), New Engl J Med., 328: 238-244.

Norman GA (1991), The potential of meat of the goat. Developments in meat science (Ed.) Lawrie RA, Elsevier Applied Science, London.
Paul AA and Southgate DAT (1978), McCance and Widdowson's the Composition of Foods 4th ed. London: HMSO.

Pellet PL and Young VR (1990), Role of meat as a source of protein and essential amino acids in human nutrition. Meat and health, Advances in Meat Research, Vol. 6. (Eds) Person AM and Dutson TR, Elsevier Applied Science, London.

Raheja RK, Kaur C, Singh A, and Bhatia IS (1973), Colorimetric method for the quantitative estimation of phospholipids without digestion. J. Lipid Res., 14: 695-697.

Ruxton CHS, Calder PC, Reed SC and Simpson, MJA (2005), The impact of long-chain polyunsaturated fatty acids in human health. Nutrition Research Reviews, 18: 113-129.

Sebart N, Rickert RR, Mossoba MM, Drama JKG, Yraweez MP, Roach JAG. Adolf RO, Morehouse KM, Fritsche J, Euliytz KD, Steinhart H and Ku K (1999), Improved separation of conjugated fatty acid methyl esters by silver ion-high performance liquid chromatography. Lipids, 34: 407-413.

Starks MA, Starks SL, Kingsley M, Purpura M and Jeger R (2008), The effects of phosphatidylserine on endocrine response tomoderate intensity exercise. Journal of the International Society of Sports Nutrition, 5: 11.

Storen LH, Baur, LA, Kriketos, AD, Pan DA, Cooney GJ, Tribole E (2007), The Ultimate Omega-3 Diet: Maximise the power of Omega-3 to supercharge your health, battle inflammation and keep your mind sharp. New York, USA: The McGraw-Hill.

Vaisman N, Kaysar N, Zaruk-Adasha Y, Pelled D, Brichon G, Zwingelstein G and Bodennee J (2008), Correlation between changes in blood fatty acid composition and visual sustained attention performance in children with inattention effect of dietary n-3 fatty acids containing phospholipids. The American Journal of Clinical Nutrition, 87(5): 1170-1180.

Wang Z, Klipfell E, Bennett BJ, Koeth R, Levison BS, Duqar B, Feldstein AE, Britt EB, Fu X, Chung YM, Wu Y, Schauer P and Allayee JDl (2011), Gut flora metabolism of phosphatidylcholine promotes cardiovascular disease. Nature, 472(7341): 57-63.

Received: 05 April 2015; Revised: 10 May 2015; Accepted: 30 June 2015. 